\title{
Statistical Analysis of Road Traffic Car Accident in Dire Dawa Administrative City, Eastern Ethiopia
}

\author{
Belachew Melese Hunde ${ }^{1,}$, , Zeleke Dutamo Aged ${ }^{2}$ \\ ${ }^{1}$ Department of Statistics, College of Natural and Computational Science, Samara University, Samara, Ethiopia \\ ${ }^{2}$ Department of Nursing, College of Health and Medical Science, Samara University, Samara, Ethiopia
}

Email address:

belachewmelese3@gmail.com (B. M. Hunde), belamh2015@yahoo.com (B. M. Hunde), zeledutamo@gmail.com (Z. D. Agede)

\section{To cite this article:}

Belachew Melese Hunde, Zeleke Dutamo Agede. Statistical Analysis of Road Traffic Car Accident in Dire Dawa Administrative City, Eastern Ethiopia. Science Journal of Applied Mathematics and Statistics. Vol. 3, No. 6, 2015, pp. 250-256.

doi: 10.11648/j.sjams.20150306.14

\begin{abstract}
Road traffic accidents (RTAs) have turned out to be a huge global public health and development problem. Dire Dawa City one of the federal states in North East Ethiopia has a high rate of accidents and deaths in relation to number of vehicles on the road. Realizing the need to establish baseline information on RTAs, the present study was conducted in Dire Dawa city under the jurisdiction of Dire Dawa Police Station, Dire Dawa, Ethiopia. Complete Road traffic car accident data of the year 2009 - 2013 from police records of Dire Dawa city Police station were studied. Data can be analyzed by using SPSS version 20.0 and MINITAB version 13.1 software. Data interpretation was done using descriptive statistics, two t-test comparison, chi-square test of independence, analysis of variance (one-way and two-way), and design of factorial experiment. The finding of this paper showed that the main cause of car accident is drivers. About $80 \%$ of car accident is resulted from the driver fault. Among the accident that resulted from the driver fault, not given priority for pedestrian contain the first position. Other factor like poor road condition, poor car condition, the absence of knowledge in traffic system, lack of ambulance and poor medical treatment are other cause and condition that increase the severity of the incident. Generally, the occurrence of car accident problem depends on defect on human factor, vehicle characteristics, road characteristics and environmental condition. The age of driver had also a significant impact on the occurrence of traffic accidents. Accidents were also highly depending on environmental factor like weather condition, type of road surface, condition of the road and joint road shape.
\end{abstract}

Keywords: Analysis of Variance, Dire Dawa Administrative City, Road Traffic Accidents

\section{Background of the Study}

Transportation is the vital sector that the other sector of the economy, the movement of person or material from where they are to where they like preferred are served through means of transportation. There are many problem related to transportation, but car accident is one and extensively distribution throughout the world. A car accident is road traffic incident that usually involves one road vehicle colliding with another vehicle or other road user, animal, or stationary roadside object and may result properly damage, injury and possibly death.

Road traffic accident is a major but neglected public health challenge. The World report on road traffic accident prevention has indicated that worldwide, an estimated 1.2 million people died in road traffic accident each year and as many as 50 million are being injured [1]. Current and projected trends in motorization indicated that the problem of Road traffic accident will get worse, leading to a global public health crisis. It has been indicated that, accordingly, by 2020 traffic accident is expected to be the third major killer after HIV/AIDS and TB [2]. Due to its perception as a 'disease of development', road traffic accidents and related injuries tend to be under recognized as major health problems in developing countries. According to WHO report, $90 \%$ of the world's fatalities on the roads occurred in low-income and middle-income countries, which have only $48 \%$ of the world's registered vehicles [1]. For example, an estimated total of 227,835 pedestrians died in low-income countries, as opposed to 161,501 in middle-income countries and 22,500 in high income countries each year [3].

The severity of road traffic crashes is also likely to be much greater in Africa than anywhere else, because many vulnerable road users are involved, poor transport conditions such as lack 
of seat belts, overcrowding, and hazardous vehicle environments. The poor reporting system has also masked the magnitude of the problem in Africa. The lack of pre-hospital and hospital emergency care after accidents makes the outcome of car accidents in Africa the worst [4]. According to federal police commission report the death rate due to car accident is significantly increasing among pedestrians and passengers from time to time in Ethiopia [5]. A total of 25,110 accidents and 3,415 fatalities were recorded in Addis Ababa during 2000-2009. The majority of fatalities were pedestrian, $2970(87 \%)$ followed by passengers $297(9 \%)$ and drivers $148(4 \%)$ [6]. In 2007/8, a total of 15,082 accidents occurred in the country. Of them the number of people killed was 2,161 while 7,140 experienced non-fatal injuries (7). A report from traffic Police office of Dire Dawa city indicated that in 2005, there were a total 217 RTAs and in 2009 the total number RTAs increased to 322. Therefore, this study focused on the road traffic car accident magnitude, causes and possible intervention and analysis the problem created by road traffic car accident and its consequence in Dire Dawa city.

\section{Methods}

\subsection{Study Area}

Dire Dawa city is one of the largest cities in the eastern parts of Ethiopia, on the Dechatu River, at the foot of a ring of cliffs that has been described as "somewhat like a cluster of tea-leaves in the bottom of a slop-basin." With a latitude and longitude of $9^{\circ} 36^{\prime} \mathrm{N} 41^{\circ} 52^{\prime} \mathrm{E} / 9.600^{\circ} \mathrm{N} 41.867^{\circ} \mathrm{E}$ Coordinates: $9^{\circ} 36^{\prime} \mathrm{N} 41^{\circ} 52^{\prime} \mathrm{E} / 9.600^{\circ} \mathrm{N} 41.867^{\circ} \mathrm{E}$, which locate about $500 \mathrm{~km}$ far from Addis Ababa (the capital city of Ethiopia). Based on the 2007 Census conducted by the CSA of Ethiopia, Dire Dawa has a total population of 341,834 , of whom 171,461 are men and 170,461 women; 233,224 or $68.23 \%$ of the population are urban inhabitants. The city has many industrial and market center. It seems due to this reasons that there is a high inflow of vehicle, which coupled with fast population growth rate that exaggerated the problem of road traffic accident in the city. Car accident is extensively distributed in the city and the number of accident increase rapidly from day to day.

\subsection{Nature of Data}

The present study is based on secondary data obtained from the police records of the accident cases in Dire Dawa city Police station from February 2009 - August 2013 G.C. Besides, other relevant information's were collected from the concerned officials through interviews and personal discussions.

\subsection{Statistical Analysis}

Data were analyzed using Statistical Package for Social Sciences (SPSS) version 20.0 and MINITAB version 13.1 software. $\mathrm{P}$ value below 0.05 was considered as statistically significant.

\subsection{Data Interpretation}

The following methods were applied to analyze the data.

\subsubsection{Two Sample T - test of Independence}

Applied to test the significant different between the number of accident committed on Work day and some celebrated day (Saturday, Sunday and holydays) and the number of accident committed by young driver and old driver.

\section{Hypothesis}

$\mathrm{H}_{\mathrm{o}}: \mu_{1}=\mu_{2}$ (the mean number of accident committed on workday and celebrated day are equal)

$\mathrm{H}_{\mathrm{o}}: \mu_{1}=\mu_{2}$ (the mean number of accident committed by young driver is equal to old age driver)

Decision: reject $\mathrm{H}_{\mathrm{o}}$ if $\mathrm{P}$-value is less than $\alpha$ - level of significant

\subsubsection{Chi-square $\left(\chi^{2}\right)$ Test of Association}

Test for association or independency: Chi-square test of association is applies for testing whether there is significant different in the fatality or not among commonly observed of collision. There are two variable (categories) one is type of collision and second is severity or fatality .There are six type of collision and the severity of accident has three levels. These are fatal, medium injury and light injury.

Hypothesis:

$\mathrm{H}_{\mathrm{o}}$ : the fatality and type of accident are not associated.

$\mathrm{H}_{1}$ : the fatality and type of collision are associated.

Decision rule:

We reject $\mathrm{H}_{\mathrm{o}}$ if $\mathrm{P}$-value is less than $\alpha$ - level of significant or the calculated chi-square value less than the tabulated value.

\subsubsection{Analysis of Variances (ANOVA)}

Analysis of variable or ANOVA is used to test a hypothesis concerning the mean of three or more than population.

One - way analysis of variance: used to test whether the number of death observed due to car accident in different type of place in the city is shown significant difference or not and whether the number of accident is significant different from the shape of the road.

\section{Hypothesis}

$\mathrm{H}_{\mathrm{o}}: \mu_{1}=\mu_{2}=\ldots=\mu_{7}$ (the mean number of accident committed is equal in all seven type of place) vs. $\mathrm{H}_{1}$ : At least one type is different.

$\mathrm{H}_{\mathrm{o}}: \mu_{1}=\mu_{2}=\mu_{3}=\mu_{4}=\mu_{5}$ (the mean number of accident equal in five kind of road shape) vs. $\mathrm{H}_{1}$ : At least one is different.

Fisher's least significant difference

Fisher multiple comparisons is applied for further comparison of mean number of accident committed in different type of place

Hypothesis:

$\mathrm{H}_{\mathrm{o}}$ : the mean of accident in the path place is equal to the path place

$\mathrm{H}_{1}$ : Not $\mathrm{H}_{\mathrm{o}}$

Decision rule: Reject $\mathrm{H}_{\mathrm{o}}$ if $\mathrm{p}$-value less than $\alpha$-level or the 
calculated value less than tabulated or the difference between the two means not include Zero.

Two-way analysis of variance: used to test whether there is significant interaction effect between the number of accident committed by types of car and types of place of accident occurred and the type of road shape and the cause car accident committed. There are five type of road shape and five cause of car accident where both of them are fixed effect.

Hypothesis for number of accident committed by types of car and types of place

For treatment $A$ (cause of accident)

$\mathrm{H}_{\mathrm{o}}: \alpha 1=\alpha 2=\alpha 3=\alpha 4=\alpha 5=0$ (The numbers of accident committed due to all five causes are equal)

For treatment $B$ (shape of road)

$\mathrm{H}_{\mathrm{o}}: \beta 1=\beta 2=\beta 3=\beta 4=\beta 5=0$ (The numbers of accident committed in all road shape are equal)

For the interaction $A$ and $B$

$\mathrm{H}_{\mathrm{o}}: \quad \alpha \beta 11=\alpha \beta 12=\cdots=\alpha \beta 55=0 \quad$ (there is interaction between the cause of accident and road shape)

Hypothesis for the type of road shape and the cause car accident committed.

For cause of accident

Ho: $\alpha 1=\alpha 2=\alpha 3=\alpha 4=\alpha 5=0$ (The numbers of accident committed due to all five causes are equal) vs. H1: At least one inequality.

For the road shape

$\mathrm{H}_{\mathrm{o}}: \beta 1=\beta 2=\beta 3=\beta 4=\beta 5=0$ (The numbers of accident committed in all road shape are equal) vs. $\mathrm{H}_{1}$ : At least one inequality.

For the inter reaction

$\mathrm{H}_{\mathrm{o}}: \alpha \beta 11=\alpha \beta 12=0$ (there is inter reaction between the cause of accident and road shape)

$\mathrm{H}_{1}$ : At least one inequality.

\subsubsection{Design of Factorial Experiment}

The effect of two or more factors on the response variable can be studied simultaneously in an experiment.

The general three factorial experiments: the general three factorial experiments is applied for testing the individual and interaction effect of weather condition, shape of road and the type of road surface on the occurrence of accident.

For interaction of $A, B$ and $C$

$\mathrm{H}_{0}: \quad \alpha \beta \gamma 111=\alpha \beta \gamma 112=\alpha \beta \gamma 123=\ldots . . \alpha \beta \gamma$ abc (there is no three interaction effect between shape of road, road surface and weather condition).

Hypothesis:

For factor A (shape of road)

Ho: $\alpha 1=\alpha 2=\alpha 4=\alpha 5=0$ (the number of accident is the same on all kind road shape)

For factor $B$ (road surface)

Ho: $\beta 1=\beta 2=\beta 3=\cdots \beta 4=0$ (The numbers of accident committed on difference type of road surface are the same).

For factor $C$ (weather condition)

Ho: $\gamma 1=\gamma 2=\gamma 3=\cdots .=\gamma c=0$ (the number of accident committed at different air condition has not difference).

\section{For interaction of $A$ and $B$}

Ho: $\alpha \beta 11=\alpha \beta 12=\cdots=\alpha \beta \mathrm{ab}=0$ (shape and type of road surface has not interaction effect on the occurrence of car accident).

For interaction of $A$ and $C$

Ho: $\alpha \gamma 11=\alpha \gamma 12=\ldots .=\alpha \gamma a c=0$ (shape of road and air condition has no interaction effect on the occurrence car accident).

For interaction of $B$ and $C$

Ho: $\beta \gamma 11=\beta \gamma 12=\cdots .=\beta \gamma b c=0$ (shape of road, road surface and air condition has not interaction effect on the occurrence of car accident).

Decision: Reject the null hypothesis if F-calculate is greater than tabulation value or p-value is less than $\alpha$-level.

\section{Results}

\subsection{Descriptive Statistics}

Table 1. Descriptive Statistics: death, heavy injury, light injury, number of accident.

\begin{tabular}{lllllll}
\hline Variable & Mean & StDev & Minimum & Maximum & Q1 & Q3 \\
\hline $\begin{array}{l}\text { death } \\
\text { heavy }\end{array}$ & 21.20 & 3.83 & 16.00 & 26.00 & 17.50 & 24.50 \\
$\begin{array}{l}\text { injure } \\
\text { light }\end{array}$ & 47.20 & 12.85 & 31.00 & 63.00 & 34.50 & 59.00 \\
$\begin{array}{l}\text { injure } \\
\text { no of } \\
\text { accident }\end{array}$ & 88.40 & 12.70 & 72.00 & 104.00 & 77.50 & 101.00 \\
\hline
\end{tabular}

From Table1 the calculated mean number of death, heavy injury, light injury and number of accident was $21,47,88$ and 276 respectively. From the value of their StDev, the numbers of accident showed more variation in five-year period, but the number of death is showed less variation.

About $80 \%$ of accident was committed by driver fault or factor (see Figure1). Driver factor includes like driver error, intoxication, not giving priority for pedestrian and other vehicle and other human factor. Defect on road design and maintenance accounted about $9 \%$ of accident, and took the second place for cause of car accident. The defect on road either noted as making a significant contribution to the circumstance of the crash, or not allowed for recovery. In these circumstances, it is frequently the driver who is blame rather than the road; those reporting the accident have tendency to overtake the human factor involved, such as the subtlety compensate for it. Weather and environmental condition totally accounted about $6 \%$ the accident occurred. This factor includes bad weather condition like heavy rainfall, unsuitable temperature and dangerous topographic area. Dangerous topographic area either noted as making a significant contribution to the circumstance of the crash, or not allowed for recovery. Defect with the car accounted about $5 \%$ accident committed, and this facer includes like defect in brake, front.

Among the fault of driver not giving priority to pedestrians, took the leading position in the cause of higher number of death and injury. This implied that not giving 
priority to pedestrians was the main cause of traffic road accident and the loss of life. The second main cause for road traffic accident death and injury was over speeding. Not giving priority to vehicle took the third position and this accident mainly happened between vehicle especially at Tshape and +-shape road. Over taking and driving in left direction found at fourth and fifth place, and this accident mainly observed in straight road when driver try to pass other vehicle. Over loading, not keeping the distance between vehicle and drive after drink alcohol found at six, seven and the last position respectively.

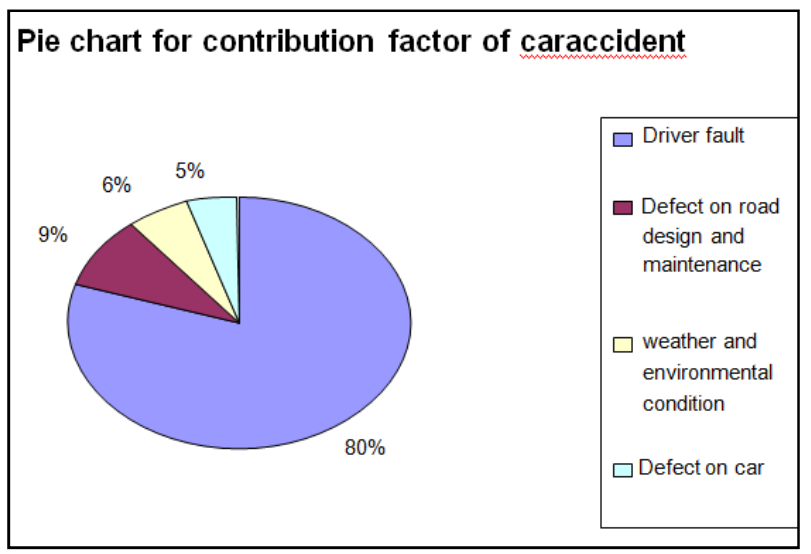

Figure 1. Pie chart for contribution factor of car accident.

\subsection{Two-Sample T-Test}

Table 2. Two-Sample t-test for Work day vs. Saturday, Sunday and holydays.

\begin{tabular}{lccc}
\hline Days & Mean & StDev & SE Mean \\
\hline $\begin{array}{l}\text { Workday } \\
\text { Saturday, Sunday and }\end{array}$ & 82.4 & 9.7 & 3.1 \\
holydays & 90.4 & 11.0 & 4.9 \\
$\begin{array}{l}\text { Estimate for difference: }-8.00,95 \% \text { CI for difference: } \\
(-26.13,-10.13), \mathrm{t}-\text { test of difference }=0 \text { (vs. not }=\text { ); } \mathrm{t}-\text { Value }= \\
-1.02 ; \mathrm{p}=0.03, \mathrm{DF}=8, \text { PooledStDev }=12.4\end{array}$ \\
\hline
\end{tabular}

The P-value of t-test statistic for mean comparison of accident committed between work day and some celebrate day like Saturday, Sunday and holiday is less than the specify $\alpha$-level (0.05). Hence the occurrence of accident in workday and some celebration day had significant different.

The $95 \%$ confidence of interval is not including Zero in the interval; this showed that the occurrence of accident is different between workdays and holidays. This variation may come from the drinking alcohol during the last days of week and holiday by both driver and pedestrians. Another factor is many people out for marketing in holiday and higher traffic cognitions may be happened.

Table 3. Two-sample t-test for Age $<35 v$ s. Age $>35$.

\begin{tabular}{llll}
\hline Age & Mean & StDev & SE Mean \\
\hline Age $<35$ & 166.8 & 28.0 & 13 \\
Age $>35$ & 108.8 & 14.7 & 6.6 \\
Estimate for difference: $58.0,95 \%$ CI for difference: & $(25.4,90.6)$, T-Test of \\
difference $=0$ (vs. not $=$ ): T-Value $=4.1$, P-Value $=0.003$ DF $=8$, Pooled \\
StDev $=22.4$
\end{tabular}

The P-value of t-test statistic for mean comparison of accident committed between drivers whose age is less than 35 year old greater than 35 year old is less than specified $\alpha$ level. Hence, the driver whose age is less than 35 year had higher risk of committing accident than driver whose age is greater than 35 year. The driver capability is affected by the physical and mental to assess the condition and respond quickly. Although young people tend to have good reaction time, disproportionately younger driver features in accident. Young driver showed many exhibit behaviors and attitude to risk that them in the more hazardous situation. Old driver with slower reaction would be expected to be involving in more accident. However, there had been the case as tend to drive less and apparently, more cautiously.

\subsection{Chi-Square Test: For Testing the Severity of Different Type of Accident}

Table 4 indicated that the p-value of chi-square test is less than the $\alpha$-level of significant. Then, we can conclude that there is dependency or association between the type of road accident and the severity of damage. From the test one could observe the expected death for the car which rollover is 12 and the actual death occurred is 24 . The number of actual death is twice that of expected, this show rollover is fatal car accident.

Table 4. Testing the severity of different type of accident.

\begin{tabular}{lllll}
\hline & fatal & medium & easy & Total \\
\hline 1 & 738 & 45 & 90 & \\
& 11.33 & 32.16 & 46.51 & \\
2 & 5 & 31 & 61 & 97 \\
& 12.21 & 34.67 & 50.13 & \\
3 & 24 & 42 & 29 & 95 \\
& 11.95 & 33.95 & 49.09 & \\
4 & 2 & 22 & 74 & 98 \\
5 & 12.33 & 35.02 & 50.64 & \\
& 16 & 41 & 51108 & \\
6 & 13.59 & 38.60 & 55.81 & 108 \\
& 21 & 39 & 48 & \\
Total & 73.59 & 38.60 & 55.81 & \\
Chi-Sq $=$ & 62.428 DF $=10$ P-Value $=0.000$ & & \\
\hline
\end{tabular}

The next fatal accident the collision with pedestrian the expected number of death is 14 but the actual death occurred is 21 , this showed that the collision with pedestrian had higher mortality. Collision with bicycle had expected death of 14 accidents is in high risk of death. The main reasons for the fatality of cyclist have little protection other than their clothing. Side or angle collision, Head on collision and Rear impact collision had lower actual death than expected.

\subsection{Analysis of Variances (ANOVA)}

The P-value analysis of variance for the number of death occurred in different kind of place is less than our $\alpha$-level (0.05) of significant. Then, investigation concluded that the 
type of place had significant effect on the number of accident committed and death. To decide which pairs of treatment are different we use fisher least significant difference.

Table 5. One-way ANOVA for Number of death vs. type of accident place.

\begin{tabular}{llllll}
\hline Source & DF & SS & MS & F & P \\
\hline Factor & 42.69 & 7.11 & 6 & 6.00 & 0.000 \\
Error & 28 & 33.20 & 1.19 & & \\
Total & 34 & 75.89 & & & \\
\hline
\end{tabular}

Fisher's pair wise comparisons

$\mathrm{H}_{\mathrm{o}}: \mu_{\mathrm{i}}-\mu_{\mathrm{j}}=0$ vs. $\mathrm{H}_{1}: \mu_{\mathrm{i}}-\mu_{\mathrm{j}} \neq 0$ for $\mathrm{i} \neq \mathrm{j}$

Intervals for (column level mean) - (row level mean)

\begin{tabular}{|c|c|c|c|c|c|c|}
\hline & Churches & Factories & Hospital & Market & Offices & Residence \\
\hline \multirow{2}{*}{ Factories } & 0.59 & & & & & \\
\hline & 3.410 & & & & & \\
\hline \multirow{2}{*}{ Hospital } & -0.610 & -2.610 & & & & \\
\hline & 2.210 & 0.210 & & & & \\
\hline \multirow{2}{*}{ Market } & 2.010 & -4.010 & -2.810 & & & \\
\hline & 0.810 & -1.190 & 0.010 & & & \\
\hline \multirow{2}{*}{ Offices } & -3.010 & -5.010 & -3.810 & -2.410 & & \\
\hline & -0.190 & -2.190 & -0.990 & -0.410 & & \\
\hline \multirow{2}{*}{ Residence } & -0.810 & -2.810 & -1.610 & -0.210 & 0.790 & \\
\hline & -2.010 & -0.010 & 1.210 & 2.610 & 3.610 & \\
\hline \multirow{2}{*}{ school } & -0.210 & -2.210 & -1.010 & 0.390 & 1.390 & 0.810 \\
\hline & 2.610 & 0.610 & 1.810 & 3.210 & 4.210 & 2.010 \\
\hline
\end{tabular}

The above fisher multiple comparisons contains the confidence interval of the difference for each pair of treatment group. Among the pairs, the difference between death occurred at office and all other place is not include zero. So, the number death occurred at office is larger than other. As most of the office, especially business offices are found near or follow main road. They will be crowded with people and the vehicle during peak hour. Thus, violation of traffic rule and regulation (such as over speeding, overtaking other vehicle unlawfully, etc) is likely resulted in traffic accident. Religious place market and residential place also had higher death next to office.

One -way ANOVA for the shape of the road vs. number of accident

From Table 6, the p- value of the analysis of variance for the shape of the road and the number of accident committed is less than our $\alpha$-level of significant. Then, we concluded that the shape of road had significant effect on the number of accident committed. To decide which pairs of treatment are different, we use fisher least significant difference.

Table 6. One-way ANOVA: no of accident versus road shape.

\begin{tabular}{llllll}
\hline Source & DF & SS & MS & F & P \\
\hline road shape & 4 & 5792.6 & 1448.1 & 32.85 & 0.000 \\
Error & 20 & 881.6 & 44.1 & & \\
Total & 24 & 6674.2 & & & \\
\hline
\end{tabular}

Fisher's pair wise comparisons

$\mathrm{H}_{\mathrm{o}}: \mu_{\mathrm{i}^{-}} \mu_{\mathrm{j}}=0$ vs. $\mathrm{H}_{1}: \mu_{\mathrm{i}^{-}} \mu_{\mathrm{j}} \neq 0$ for $\mathrm{i} \neq \mathrm{j}$

The below fisher multiple comparisons contains the confidence interval of the difference for each pair of treatment group. This allows assessing the practical significant between among mean of accident committed on different type of road.

Intervals for (column level mean) - (row level mean)

\begin{tabular}{lllll}
\hline & +-shape & circle & straight & T-shape \\
\hline circle & -14.641 & & & \\
& 32.159 & & & \\
straight & -24.159 & -47.559 & & \\
& -6.641 & -30.041 & & \\
T-shape & -7.441 & -15.959 & 22.841 & \\
& 24.959 & 1.559 & 40.359 & \\
Y-shape & -15.241 & -8.159 & 30.641 & -0.959 \\
& 32.759 & 9.359 & 48.159 & 16.559 \\
\hline
\end{tabular}

The different between the mean number of accident committed on straight road without joint and all other kind of road shape is not included zero. Then, we can conclude that there was significant difference between mean of number of accident occurred at straight road and other road shape. Most of the difference between the mean accident occurred of the other pair of group has zero. So, we conclude that there was no significance difference occurrence of accident between those groups. The main factor that the number of accident committed on straight road is greater than driving above the allowable speed.

\subsection{Two-Way ANOVA}

Table 7. No of accident versus places and types of car.

\begin{tabular}{llllll}
\hline Source & DF & SS & MS & F & P \\
\hline places & 3 & 6343 & 2114 & 4.86 & 0.028 \\
types of car & 3 & 28373 & 9458 & 21.72 & 0.000 \\
Error & 9 & 3919 & 435 & & \\
Total & 15 & 38635 & & & \\
\hline
\end{tabular}

The $\mathrm{p}$-value for the treatment group or the type of car is less than the specified $\alpha$-level of significant. Hence, there is significant difference effect difference on the occurrence of accident among five kinds of car. That is (Tax, three wheel vehicle, Minibus and Isuzu). From the 95\% confidence interval for mean number of accident committed by different type of Vehicle, the number of accident committed by tax and three wheel vehicles had not significant difference. The main cause for this result was the rapid increase in number of three-wheel vehicle replacing of tax service. However, there is evident variation in the number of accident committed by tax and three-wheel vehicle compared to other.

\subsection{Two - Way ANOVA}

Table 8. Number of accident vs. cause of accident and shape of road.

\begin{tabular}{llllll}
\hline Source & DF & Seq SS & MS & F & P \\
\hline shape & 4 & 9904.8 & 2476.2 & 119.8 & 0.004 \\
cause & 4 & 9449.6 & 2362.4 & 100.9 & 0.025 \\
shape*cause & 16 & 51189.6 & 3199.3 & 56.2 & 0.009 \\
Error & 25 & 478 & 19.2 & & \\
Total & 49 & 71022.0 & & & \\
\hline
\end{tabular}


The P-value for the column factor (cause of accident and shape of road) is statistically significant. This showed that there was significant difference between the numbers of accident committed due to these factors. The P-value for interaction of two variables (shape of road and cause of accident) was statistically significant. This implied that there is an interaction effect, which maximizes or minimizes the occurrence of accident between the two variables.

\subsection{Analysis of Variance for the General Three Factorial Experiments}

Table 9 indicated that except road surface, the P-value for each individual factor is statistically significant. Thus, the occurrence of accident was significantly affected by weather condition and shape of road.

General Linear Model: Number of accident versus shape, road surface and weather condition.

Table 9. Response versus shape, road surface, weather.

\begin{tabular}{lllllll}
\hline Source & DF & Seq SS & Adj SS & $\begin{array}{l}\text { Adj } \\
\text { MS }\end{array}$ & F & P \\
\hline $\begin{array}{l}\text { shape } \\
\text { road surface }\end{array}$ & 4 & 4101.9 & 4101.9 & 1025.5 & 3.54 & 0.032 \\
$\begin{array}{l}\text { weather } \\
\text { shape*road }\end{array}$ & 1 & 4915.2 & 4915.2 & 4915.2 & 4.8 & 0.043 \\
$\begin{array}{l}\text { surface } \\
\text { shape*weather }\end{array}$ & 8 & 14407.7 & 14407.7 & 1801.0 & 8.2 & 0.005 \\
$\begin{array}{l}\text { road } \\
\text { surface*weather } \\
\text { shape*road }\end{array}$ & 2 & 540.8 & 540.8 & 270.4 & 1.96 & 0.020 \\
$\begin{array}{l}\text { surface*weather } \\
\begin{array}{l}\text { Error } \\
\text { Total }\end{array}\end{array}$ & 8 & 32444.5 & 32444.5 & 4055.6 & 2.86 & 0.039 \\
\hline
\end{tabular}

The P-value for the two interaction effects of shape of road * road surface, shape of $\operatorname{road}^{*}$ weather and weather condition*road surface were significant. This showed that the interaction of those factors had significant effect on the occurrence of car accident. The P-value for the interaction of those three factors was also significant; hence, the interaction of those factors had effect on the occurrence of accident. The interaction effect of three-factor showed that there is condition where the occurrence of accident effect of three-factor showed maximum or minimum. For instance from table the occurrence of accident when the road surface is good asphalt, at good weather condition and the road without joint is maximum. Conversely, there is minimum number of accident occurrence at condition when the road is not asphalt at cloudy weather condition and at circle place. It has safely said that many places, which look difference dangerous, did not have accident or very few. Conversely, a location that did not look difficult or dangerous may have a high crash frequency. If the driver perceiver allocation as hazardous, they take more care and there is no accident. Accident happened where hazardous road or traffic condition are not obvious at glance.

\section{Discussion}

The aim of this study was to identify the major factors that affect the occurrence of traffic accidents at Dire Dawa city, eastern Ethiopia based on secondary data obtained from the police records of the accident cases in Dire Dawa city Police station. Methods used for data analysis were Chi-square, two sample t-tests, ANOVA and design of factorial experiment.

The overall findings of this study indicate that the prevalence of road traffic accidents was associated with various factors. In Dire Dawa city, nearly $80 \%$ of the risk factors were associated with driver fault (human risk behavior) which is a similar finding to a study conducted in Mekele town, where $96 \%$ of the causes of road traffic accidents were related to human risk behavior [8].

Not giving priority to pedestrians is the most potent contributor to road traffic accidents in Dire Dawa city and some other countries like Nigeria and India [9]. For example, a study conducted in India indicated that human characteristics, such as rushing and negligence make up $95.4 \%$ of the total road traffic accidents [10].

Speeding is another factor which took the second place crashes in Dire Dawa city. In Amhara National Regional State, Ethiopia, the speed factor alone accounted for more than $31.5 \%$ of the crash. Reducing vehicle speed was one of the most effective interventions employed to stem traffic crashes on Amhara region roads [11].

The majority of accidents were occurring by drivers whose age is less than 30 years and the minimum accidents were occurring by drivers whose age is greater than 30 years old. The study concluded that as age of drivers' increase the occurrence of accidents will minimize. The majorities of accidents at Dire Dawa city were due to pedestrian's wrong crossing of the road and this study concluded that awareness should make for the communities by the responsible body to decrease accidents at city. Poor pedestrians manner in giving priorities to vehicles where necessary was statistically significant factors for the occurrence of road accidents at Dire Dawa city and the study concluded that there is better to make awareness for pedestrians to minimize the traffic accident in the area.

\section{Conclusion and Recommendation}

The result of the study revealed that the occurrence of accident depends on the defect of one of the following characteristics. These are: human factor, vehicle characteristics, road characteristics and environmental condition. Human factor include drivers and pedestrians (in most case, the victims). The finding of the study indicated that accident was caused by driver fault, especially by not giving priority to pedestrians which account $48 \%$ of the total accident. The age driver, Have also a significant impact on the occurrence of traffic accidents. Accident is also highest depending on environmental factor like weather condition, type of road surface, the condition of the road and the shape of the road joint. The finding of this study also indicated that most traffic accident occurred in the city are at good air condition on good asphalt and road with no joint. Accident committed at workday show less value when compared to 
accident occurred at holiday and the last day of week. This evident variation may come from drinking alcohol and chewing chat both driver and pedestrians those celebrated days.

\section{Abbreviations}

$\begin{array}{ll}\text { AIDS } & \text { Acquire Immune Deficiency syndrome } \\ \text { ANOVA } & \text { Analysis Of Variance } \\ \text { CSA } & \text { Central Statistical Agency } \\ \text { HIV } & \text { Human Immunodeficiency Virus } \\ \text { RTA } & \text { Road Traffic Accidents } \\ \text { TB } & \text { Tuberculoses } \\ \text { WHO } & \text { World Health Organization }\end{array}$

\section{Authors' Contributions}

BM carried out the paper starting from conception, analysis, and interpretation of data and drafted the manuscript. ZD participated in data analysis and interpretation and critical review of the paper. Both authors read and approved the final draft of the manuscript.

\section{Acknowledgements}

Authors' gratitude goes to Haramaya University for financial support. The authors extend their gratitude to traffic Police office of Dire Dawa city for giving recorded information and additional updated information of RTAs.

\section{References}

[1] WHO: Global status report on road safety time for action Switzerland; 2009.
[2] Peden M, Scurfield R, Sleet D: World report on road traffic injury prevention; 2004.

[3] Naci H, Chisholm D, Baker T: Distribution of road traffic deaths by road user group: a global comparison. Inj Prev 2009, 15:55-59.

[4] Lagarde E: Road traffic injury is an escalating burden in Africa and deserves proportionate research efforts. PLos Medicine 2007, 4:0967 0971.

[5] Federal Democratic Republic of Ethiopia: Police Commission Report 2007.

[6] Yilma B, Million T, Luce T: Motor vehicle accident and fatality surveillance Addis Ababa from 2000-2009 Addis Ababa; 2010.

[7] United Nations. Case study: Road safety in Ethiopia, 2009 [Cited 23 August 2013]; Available at:URL:http://repository.uneca.org/bitstream/handle/10 855/5250/bib.\%205641

[8] Hassen A, Godesso A, Abebe L, Girma E: Risky driving behaviors for road traffic accident among drivers in Mekele City, Northern Ethiopia. BMC Research Notes 2011; 4(535):16.

[9] Atubi AO: Determinants of road traffic accident occurrences in Lagos State: Some lessons for Nigeria. International Journal of Humanities and Social Science 2012; 2(6):252-259.

[10] Goswami A, Sonowal R: A statistical analysis of road traffic accidents in Dibrugarh City, Assam, India. Division of Epidemiology and Nutrition, Regional Medical Research Centre, 2009.

[11] Fesseha Hailu Mekonnen, Sileshi Teshager: Road traffic accident: The neglected health problem in Amhara National Regional State, Ethiopia. Ethiop. J. Health Dev. 2014; 28(1). 